Zeng N., König M., and Teizer J. (2017). "Off-site Guarding: Look-ahead Supply Scheduling for Risk Indication with BIM.” In: LC3 2017 Volume II - Proceedings of the 25th Annual Conference of the International Group for Lean Construction (IGLC), Walsh, K., Sacks, R., Brilakis, I. (eds.), Heraklion, Greece, pp. 877-884. DOI: https://doi.org/10.24928/2017/0172

\title{
OFF-SITE GUARDING: LOOK-AHEAD SUPPLY SCHEDULING FOR RISK INDICATION WITH BIM
}

\author{
Ningshuang Zeng ${ }^{1}$, Markus König ${ }^{2}$, and Jochen Teizer ${ }^{3}$
}

\begin{abstract}
Modern Information and Communication Technology (ICT) make it possible to re-organize the information flow and enhance the physical flow of the Construction Supply Chain (CSC). Considering the resource status and potential risks that exist in the CSC, this paper first explores the current CSC re-organization caused by the application of Building Information Modelling (BIM) and related beneficial conditions created by ICT. It then tackles the problem of controlling risk effectively by off-site guarding the upstream of the CSC. Based on the selected approach, the concept and basic mode of a look-ahead supply schedule is proposed. Finally, results to a use case demonstrate the applicability of a look-ahead supply schedule for a resource loaded construction project.
\end{abstract}

Keywords: Look-ahead schedule, CSC, ICT, BIM, off-site guarding.

\section{INTRODUCTION}

A consensus about a stronger link between the lean management philosophy and the information technologies has been revealed as an important issue for the field of architecture, engineering, construction, and facility management (AEC/FM). Previous efforts and outcomes, which have been made to explore how manufacturing concepts can be transferred into the construction context to improve the productivity performance (e.g., Koskela 1992), become more practical with the support of modern Information and Communication Technology (ICT). From the perspective of the Supply Chain Management (SCM), it has been affirmed that the current practices and researches effectively lead to the advanced controlling and management of CSC as an integrated value-generating flow, rather than only a series of individual activities (e.g., Vrijhoef and Koskela 2000a; Sacks 2016a). Besides, modern ICT makes it possible to detach information flows from physical flows (Christiaanse and Kumar 2000a), thus providing a chance to break the barriers of the physical constraints in CSC.

Planning is essential in construction management. The key information of an ICTenabled CSC can be captured to enhance the reliability of construction planning, especially for the task of look-ahead planning (Chua et al. 1999a; König et al. 2012; Song and Eldin 2012). While traditional scheduling tools do well in project-level planning, e.g. Critical Path Method (CPM) to create a master schedule, recently, the Last Planner (e.g., Ballard 2000a; Sacks et al. 2010a) and similar systems successfully improve the look-ahead planning and commitment planning. However, the existing construction planning encounters either insufficient details of resource status and potential risks, or details

1 Ph.D. Candidate, Faculty of Civil and Environmental Engineering, Ruhr-University Bochum, Bochum, Germany, ningshuang.zeng@rub.de

2 Professor, Faculty of Civil and Environmental Engineering, Ruhr-University Bochum, Bochum, Germany, koenig@inf.bi.rub.de

3 Senior Lecturer and Researcher, Faculty of Civil and Environmental Engineering, Ruhr-University Bochum, Bochum, Germany, jochen.teizer@rub.de 
provided just for one-of-a-kind CSC in which information and experience is hard to transfer to other types. The research teams (RT-272, RT-315 and RT-344) organized by the Construction Industry Institute (CII) recommended and developed Advanced Work Packaging (AWP). Currently, AWP as an emerging planning approach is promising to improve the integration of CSC and the risk mitigation (Ponticelli et al. 2015).

Considering the supply resource status and potential risk existed in CSC, this paper first explores the current CSC re-organization caused by the application of Building Information Modelling (BIM) and related beneficial conditions created by ICT. Then, this paper defines risk controlling for the CSC upstream interface. The main participants, processes and activities of the CSC upstream are also clarified. Based on these definitions, the concept of look-ahead supply scheduling is proposed. Finally, there is a case to provide a profile for the basic understanding of the risk controlling mechanism of the look-ahead supply scheduling.

\section{Problem Statement}

Although there is a growing body of evidence that proves that ICT and BIM have enhanced traditional planning (e.g., 4D/5D BIM, real-time tracking) (Bryde et al. 2013), the basic aspects of construction planning have to be further improved: 1) it is built upon the basis of a transformation model; 2) makes use of scheduling techniques with assumptions: a) preparation for an activity has always been adequately made before the activity's schedule time; b) each activity is to be duly accomplished (Chua et al. 1999b).

The transformation model has been criticized by researches from the perspective of the Lean Construction philosophy. Meanwhile, the Last Planner System (LPS) has been continuously developed to support better look-ahead planning and committing planning (Ballard 2000b), which is capable of breaking the constraints of the above assumptions. In most of the current LPS or related systems, the resource applying has been set as a simple constraint without a good traceability, but the peculiarity and complexity of CSC were ignored. To improve it, Sacks et al. (2010b) suggested the trade contractor's manager to select and claim the building elements in a BIM system, in order to transfer the responsibility to the person who actually is most familiar to the off-site production process. However, the look-ahead mechanism has not been improved adequately. For example, the supply problem of building component $M$ is identified in the first weekly meeting of a three-week look-ahead schedule of construction task N, as shown in Figure 1:

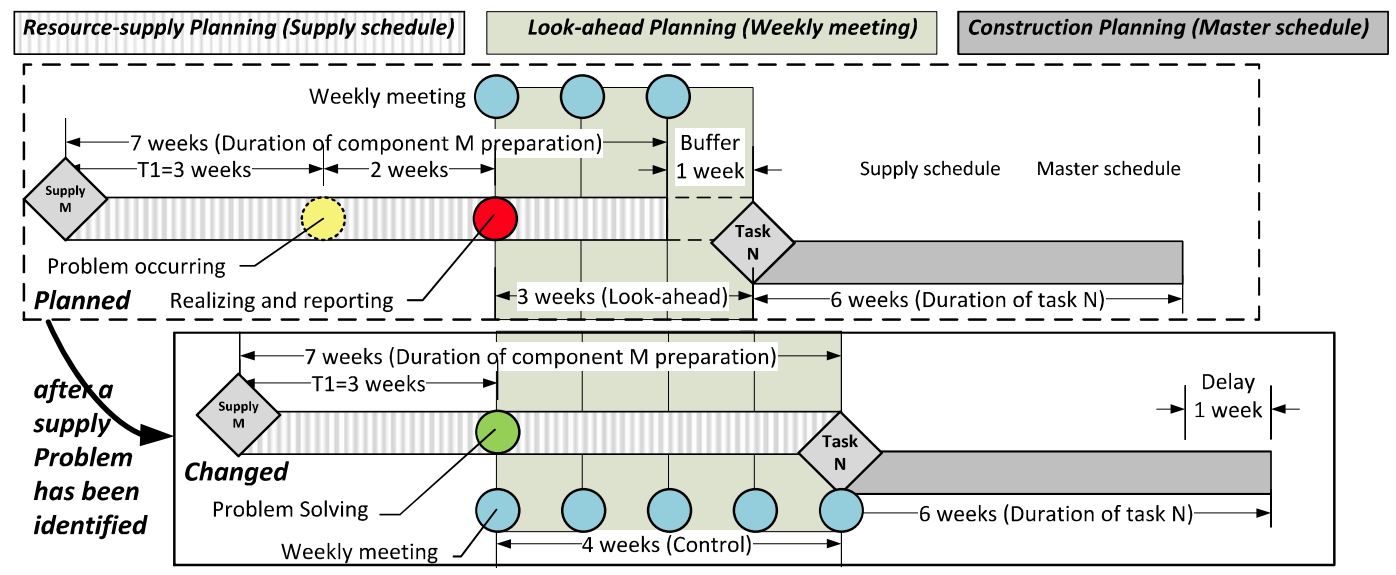


Figure 1: Inefficiency in current CSC look-ahead planning

Hypothetically, the solution can be immediately put into effect. But the problem has occurred just two weeks before the first weekly meeting, thus it takes four weeks to solve this problem (e.g., re-production). Although there is already one week time buffer of the component $\mathrm{M}$ applying for Task $\mathrm{N}$, it will still cause a one week delay in the construction master schedule. An emergency measure (e.g., replacement of supplier) can be taken when the problem is identified, but this option is often unavailable or unmanageable.

Consequently, there are two inefficient aspects of current CSC look-ahead planning to indicate the risk and further to avoid the construction delay and loss:

- the pre-processes and lead-time of the required products are different, and general duration of construction activity-based look-ahead schedule is hard to match it, e.g., even in a look-ahead planning, the long lead-time may turn pre-controlling into post-controlling;

- the activities of on-site construction and off-site production and transportation are separated, but the risks are shared and even transferred incrementally with a Bullwhip Effect. It means the post-controlling is inefficient to avoid loss.

Therefore, an efficient look-ahead supply schedule should be developed to provide realtime information for the look-ahead construction planning and indicate the risk along the whole CSC. Currently, there are favourable conditions to support it: 1) better understanding of Production theory and SCM theory: for instance, CODP (Customer Order Decoupling Point) approach makes the off-site production processes more detailed and structured; 2) the utilization of ICT: it changed the current organization of CSC, especially when BIM was adopted and developed in the construction industry.

\section{OFF-SITE GUARDING CONCEPT FOR THE CSC UPSTREAM}

Christiaanse and Kumar (2000b) summarized the related literature and explained the ICTenabled re-organization of the supply chain. It is feasible to collect and process the CSC information electronically, in advance or in parallel with the physical production flow. BIM can integrate processes throughout the entire lifecycle of a construction project. Project stakeholders have prior access to influence the on-site construction. An example of CSC re-organization in BIM scenario is shown as Figure 2:

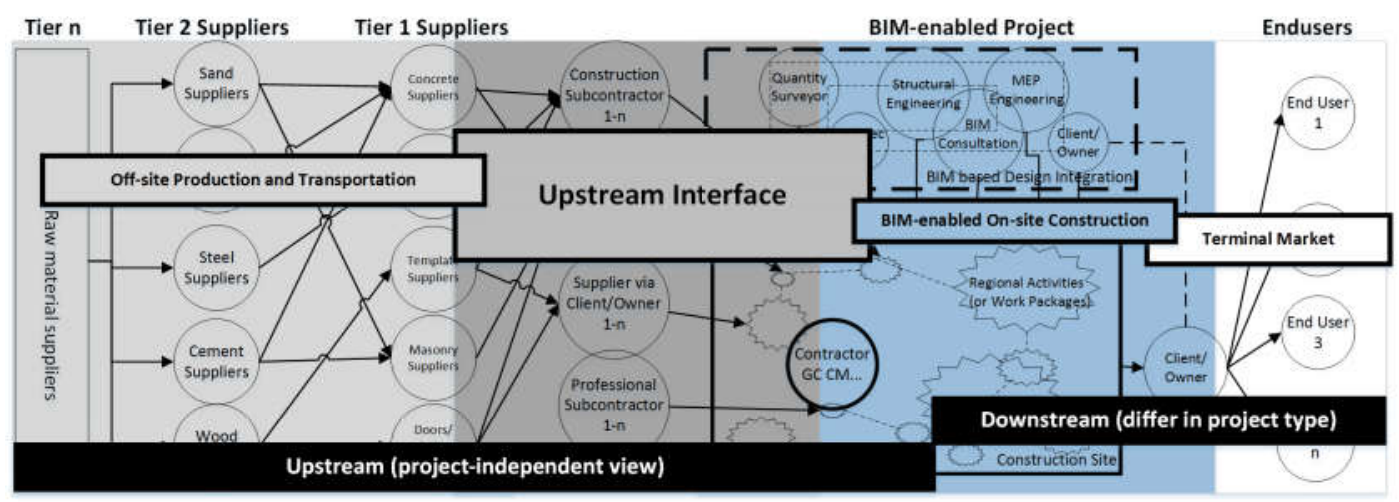

Figure 2: CSC upstream interface in BIM scenario

As the first role which has already been defined by Vrijhoef and Koskela (2000b), the focus of the upstream interface is on the impacts of the supply chain on-site activities. In 
BIM scenario, the upstream interface is the main issue of controlling the supply risk. The main participants of the upstream interface are (see Figure 3): 1) off-site participants: including General Supplier (suppliers via the general contractor), Appointed Supplier (suppliers via the client/owner), Subcontractor (responsible for one or more suppliers), other type of participants with similar function and responsibility. 2) on-site participants: including General Contractor, Construction Manager, other type of participants with similar function and responsibility; 3) joint participants (if any): including Trade Manager, Joint Logistics Manager and other type pf participants with similar function and responsibility.

Present BIM systems can provide an informative and interoperable environment for on-site construction and become more friendly to on-site participants and joint participants. However, the off-site information has not been adequately grasped and processed in BIM to support on-site construction.

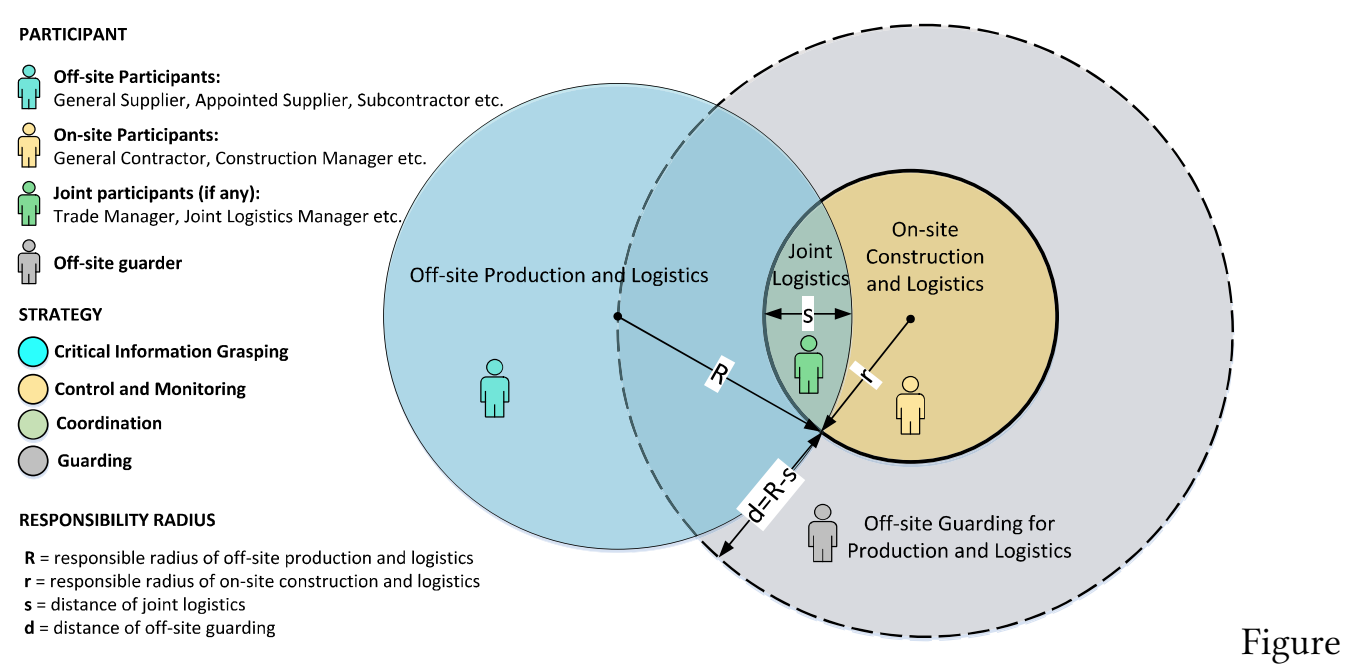

3: Participants, responsibility radius and strategy of the off-site guarding

For a holistic and look-ahead CSC risk controlling a reactive guarding mechanism is needed, as shown in Figure 3. The off-site guarding area can be interpreted as distance and time buffering to correct errors and solve problems, in order to avoid the interruption of the on-site construction. The off-site guarder refers to the person, group or even an information agent (e.g., extended BIM), which is able to grasp key information from the CSC upstream, analyze the risk degree for on-site construction in advance. In this paper, the concept of off-site guarding and the application of BIM to indicate risks is proposed.

\section{LOOK-AHEAD SUPPLY SCHEDULING FOR GUARDING}

In the ICT-enabled CSC upstream, a look-ahead supply scheduling for off-site guarding is necessary and achievable. The basic mode is designed as following:

- objects and activities: the required supply items for on-site construction are the main objects of look-ahead planning, including material, machinery, special building components etc., which comprise the physical flows of the CSC upstream. Along with the physical flow, there are a series of activities, e.g., production, transaction, transportation etc. In the look-ahead supply schedule, the production activities are most unfamiliar and uncontrollable for the on-site construction 
manager, while the transportation activities have been improved prominently by modern sensing and tracking technology (e.g., Costin et al. 2012). Thus, the offsite production activities are the main activities of look-ahead supply scheduling.

- processes: the off-site production activities are to be expressed as the CODP-based processes, to schedule the lead-time of specific supply objects. Per the CODP-based classification, there are four types of processes with different lead-time from long to short: engineered-to-order (ETO), followed by made-to-order (MTO), assembled-to-order (ATO), finally made-to-stock (MTS).

- risk identification and state-transition: the risks in the CODP-based process need to be identified by checking. The high-frequent checking is aimless and wasteful, so that a state-transition checking is applied. The state-transition information needs to be collected from direct suppliers and manufacturers, and the checking system is responsible to calculate the risks, as following:

$$
\mathrm{R}_{\mathrm{d}}=\sum_{i=1}^{n}\left(s_{\mathrm{i}}{ }^{*} \sum_{j=1}^{m} t f_{\mathrm{j}}\right) \quad \mathrm{n}=\text { the number of check points }
$$

$\mathrm{m}=$ the number of the additional events at a certain check point

$\mathrm{s}=$ the probability of the additional events occurring

$\mathrm{tf}=$ the float time of each additional event

- linking for look-ahead: the dynamic supply schedule needs to be linked with the construction schedule to indicate the risks in CSC upstream, which will be transfer into on-site construction activities.

- BIM model view: the construction manager is quite familiar with on-site construction processes but not good at handling the off-site production, so that the look-ahead risks are design to be visualized in BIM model.

In this pattern, the look-ahead supply schedule has the following basic functions: 1) it introduces off-site production into on-site construction by linking the items' lead time; 2) it provides more distinct supply information to distinguish risks to avoid supply delay or logistic disorder; 3) it proves more detailed time parameters for a construction task but will not disturb the construction sequences.

\section{CASE STUDY}

The case study that was investigated, has been developed by the Zejin Real Estate Development Co., Ltd. The project is located in Chongqing City, China. The problem has occurred in the process of hollow floor system construction. The 500/500/280 mm GBFembedded-filler was the one of the major material of the hollow floor. The GBF-embeddedfillers is placed on the floor to improve the floor's void ratio. It also accelerates the construction schedule. The problem of the delay of the supply of the material occurred. At the beginning, it was late between one and up to two weeks. Later, the supply was late for a month. This matter led to the idling of the labour forces and the damage of the framework that contained steel reinforcement under high-temperature conditions. The causes finally led to project delay and cost increase. Although the kind of fillers is an MTO product and the production process is not complicated, it is a new material for use in the Chinese residential construction. There was no experienced supplier in the Chongqing region and the general contractor has not prepared any preventive measure. 


\subsection{Linking the CODP supply schedule with construction schedule}

The following look-ahead supply schedule is suggested in this use case. As shown in Figure 4, the related construction tasks can be defined: 1) floor slab formwork and rebar binding; 2) GBF-embedded-fillers installing and concrete casting. Each construction task needs different types of materials or equipment based on the CODP-classification.

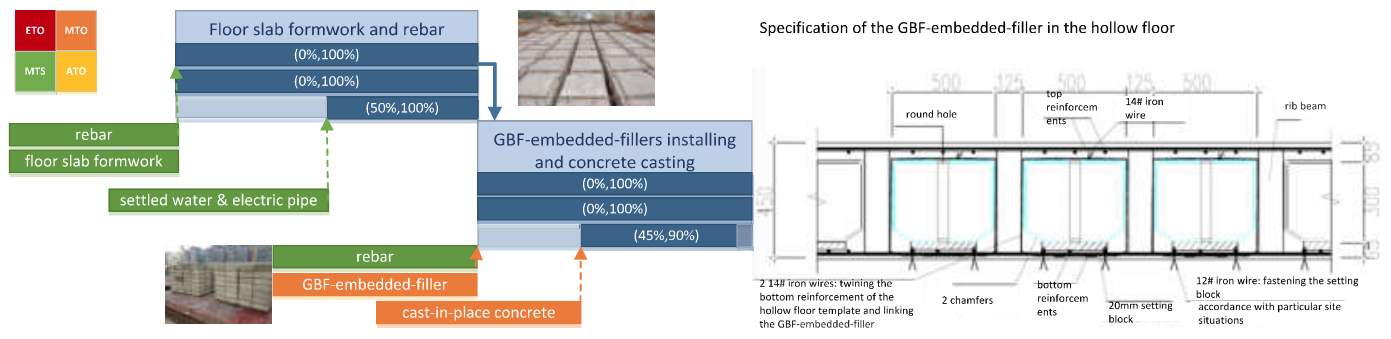

Figure 4: CODP-based schedule of the GBF-embedded-filler

The specific CODP-based process is designed to provide the necessary detail. It supplies a series of key state-transitions and makes the off-site production flow clear and manageable. However, in this use case, the construction manager did not get the key information from the supplier and consequently caused a construction delay. To avoid the problem in the future, it is necessary to define and check the specific MTO production process of the GBF-embedded-filler in advance.

\subsection{Process definition and state-transition for supply risk identifying}

To grasp the key information of state-transition is the task for a general contractor or construction manager in the off-site guarding stage. There are three state-transition check points in the MTO process of the GBF-embedded-filler, as shown in Figure 5:

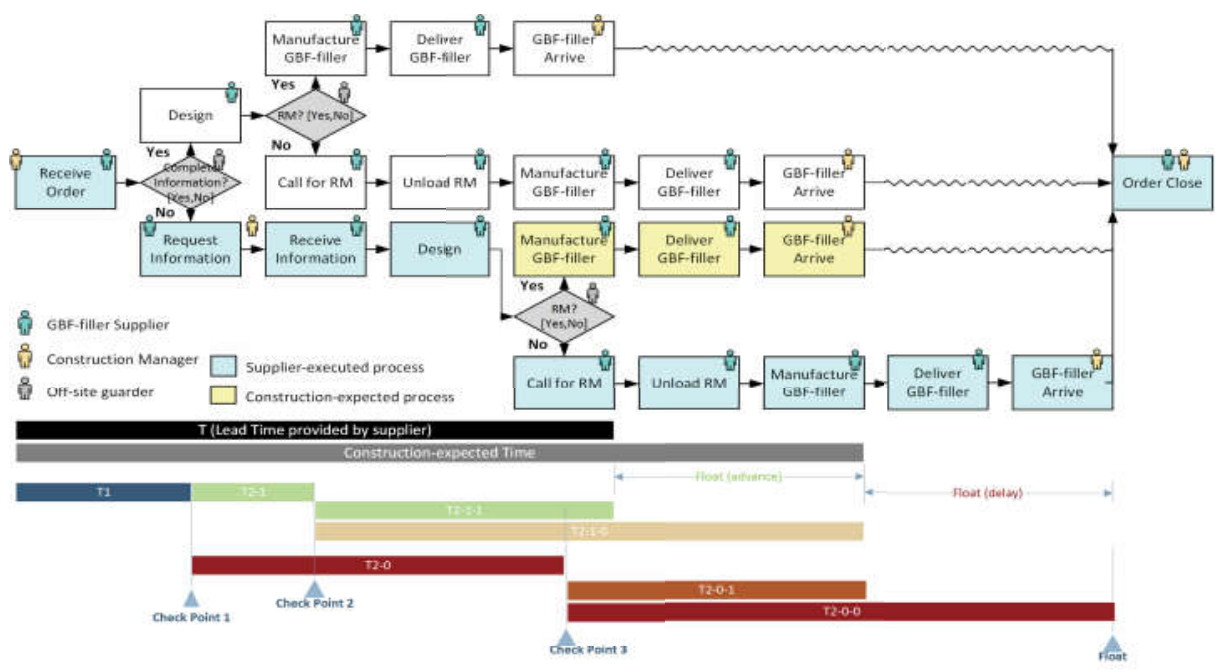

Figure 5: State-transition checking of the GBF-embedded-filler

There are also three off-site guarders of state-transition, and they are responsible for keeping robust information flow and providing key information for look-ahead planning. In this ICT-enabled CSC upstream, they are set as the information agents rather than the 
natural person, to play a role in BIM system. Every state-transition checking can work out the risk level, which will be stored in the off-site guarding information agent. This checked and stored risk level information will be visualized in BIM system for construction manager's look-ahead planning and controlling.

In this case, the general contractor has already asked the supplier at the first check point, and the supplier promised it after completing the design information. However, the following supplier-executed process and the construction-expected process was not met, as shown in Figure 5. The second state-transition has not been checked: if the raw materials (RM) get ready or not? The supplier met the problem after the design phase without giving any information to the general contractor. If the general contractor would have known about the situation in advance, he possibly could have slowed down the construction task of floor slab formwork and rebar binding to avoid the damage to the framework containing the steel reinforcement in the high-temperature condition.

\subsection{Supply risk indication in BIM for construction look-ahead planning}

The supply risk indication in BIM model view is easy for the general contractor and subcontractors to understand. Zeng et al. (2015) have discussed how to add CODP-based parameters in BIM and how to express the risk value. The function mock-up is shown in Figure 6:

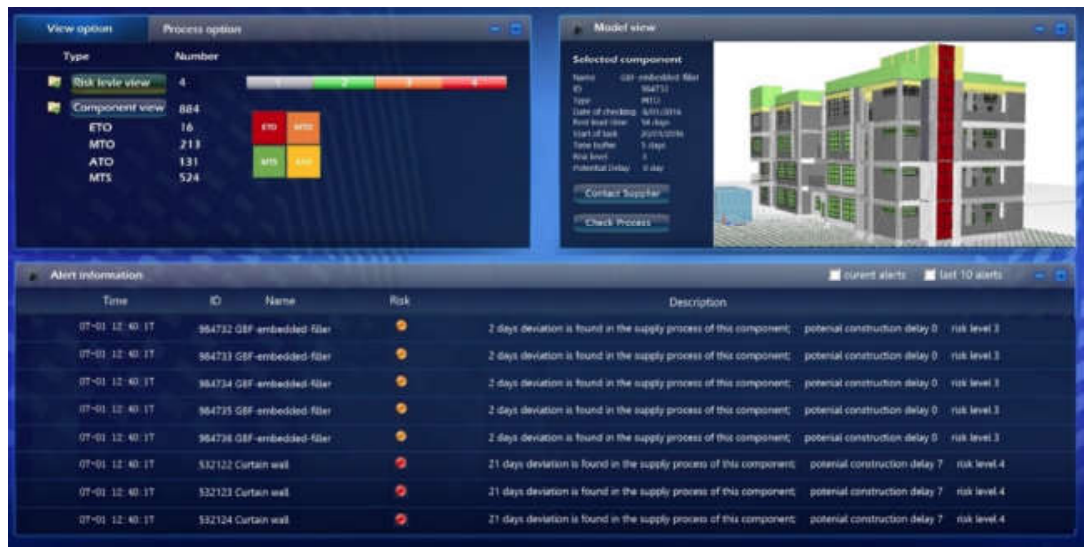

Figure 6: Function mock-up of supply risk indication in BIM

There are two elements in identifying the supply risk: 1) BIM model view, and 2) supply process inquiring. In the view option, the risk level view and the component view can be selected. The risk level view is shown in the right window. The model view will indicate the supply risk in a colour scheme and provide the basic information of the selected components. There is also an alert window, which contains the information about time, component name and ID, risk level and delay description. If it is necessary to find out details to the supply problem, the 'check process' function will help and a new window of the CODP-based process opens for further checking.

\section{CONCLUSION}

This paper explored the current CSC re-organization caused by the application of BIM. The novel information created by ICT defined the off-site guarding in the CSC upstream. Based on these definitions, the concept of look-ahead supply scheduling is proposed. Finally, a case study provided the basic understanding of integrating the functionality of 
CSC upstream interface and the risk controlling mechanism of the look-ahead supply scheduling in practice.

Findings are that generating a look-ahead supply schedule does not interrupt the behavioural pattern of the on-site construction manager for the look-ahead planning and weekly meetings, but BIM enriched with supply information provides more completed and real-time information for decision making. However, further methods need to be developed and tested to build a robust look-ahead supply linkage. This then will enable users to allocate and control the activities and resources more efficient and ultimately causing lower risk to the project.

\section{REFERENCES}

Ballard, H.G., (2000). The last planner system of production control. The University of Birmingham.

Bryde, D., Broquetas, M. and Volm, J.M., (2013). The project benefits of building information modelling (BIM). International Journal of Project Management, 31(7), pp.971-980.

Christiaanse, E. and Kumar, K., (2000). ICT-enabled coordination of dynamic supply webs. International Journal of Physical Distribution \& Logistics Management, 30(3/4), pp.268-285.

Chua, D., Jun, S. and Hwee, B., (1999). Integrated production scheduler for construction look-ahead planning. Proc. 7th Ann. Conf. Intl. Group, pp.287-298.

Costin, A., Pradhananga, N. and Teizer, J., (2012). Leveraging passive RFID technology for construction resource field mobility and status monitoring in a high-rise renovation project. Automation in Construction, 24, pp.1-15.

König, M. et al., (2012). Intelligent BIM-based construction scheduling using discrete event simulation. Proceedings of the 2012 Winter Simulation Conference, pp. 1-12.

Koskela, L., 1992. Application of the new production philosophy to construction. Tech. Report, pp.37-62.

Ponticelli, S., O’Brien, W. J., and Leite, F. (2015). Advanced work packaging as emerging planning approach to improve project performance: case studies from the industrial construction sector. Available at: http://dx.doi.org/10.14288/1.0076409

Sacks, R., 2016. What constitutes good production flow in construction? Construction Management and Economics, 34(9), pp.641-656.

Sacks, R., Radosavljevic, M. and Barak, R., 2010. Requirements for building information modeling based lean production management systems for construction. Automation in construction, 19(5), pp.641-655.

Song, L. and Eldin, N.N., 2012. Adaptive real-time tracking and simulation of heavy construction operations for look-ahead scheduling. Automation in Construction, 27, pp.32-39.

Vrijhoef, R. and Koskela, L., 2000. The four roles of supply chain management in construction. European Journal of Purchasing \& Supply Management, 6(3-4), pp.169178.

Zeng, N. et al., 2015. Supply Chain Modeling for BIM-oriented Construction Schedule Management: CODP-based Classification Approach. In Proc. of the 32nd CIB W78 Conference 2015, Eindhoven, The Netherlands. 